\title{
First-Principles Insight into the Effects of Intrinsic Oxygen Defects on Proton Conduction in Ruddlesden-Popper Oxides
}

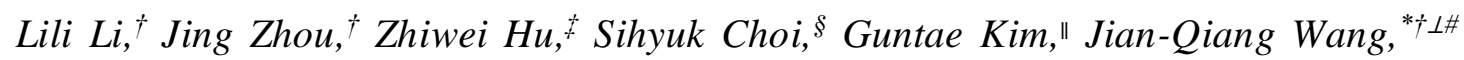
Linjuan Zhang, ${ }^{*}+\perp \#$

$\dagger$ Key Laboratory of Interfacial Physics and Technology, Shanghai Institute of Applied Physics, Chinese Academy of Sciences, Shanghai 201800, China

†Max Planck Institute for Chemical Physics of Solids, Nöthnitzer Strasse 40, Dresden 01187, Germany

$\S$ Department of Mechanical Engineering (Department of Aeronautics, Mechanical and Electronic Convergence Engineering), Kumoh National Institute of Technology, Gyeongbuk 39177, Republic of Korea

॥School of Energy and Chemical Engineering, Ulsan National Institute of Science and Technology (UNIST), Ulsan 44919, Republic of Korea

$\perp$ University of Chinese Academy of Sciences, Beijing 100049, China

\#Dalian National Laboratory for Clean Energy, Dalian 116023, P. R. China

*Email: wangjianqiang@sinap.ac.cn

*Email: zhanglinjuan@sinap.ac.cn 


\section{Computational details}

The present calculations were performed based on the Vienna ab initio Simulation Package (VASP) ${ }^{1,2}$ implementation of density functional theory (DFT) in conjunction with the projector augmented wave (PAW). ${ }^{3}$ Consequently, the $\mathrm{La} 4 d^{10} 5 d^{1}, \mathrm{Sr} 3 d^{10}$, Ni $3 d^{8} 4 s^{2}$, Co $3 d^{7} 4 s^{2}$, Fe $3 d^{6} 4 s^{2}$, and O $2 s^{2} 2 p^{4}$ states were treated as valence electrons. The electron exchange and correlation within the generalized gradient approximation (GGA) of the Perdew-Burke-Ernzerhof (PBE) functional were used to optimize the configurations. ${ }^{4}$ The lattice parameters for the fully relaxed $\mathrm{La}_{2} \mathrm{NiO}_{4}, \mathrm{La}_{2} \mathrm{CoO}_{4}$, $\mathrm{Sr}_{2} \mathrm{CoO}_{4}$, and $\mathrm{Sr}_{2} \mathrm{FeO}_{4}$ models are shown in Table $\mathrm{S} 1$, which agree with the experimentally measured. ${ }^{5-8}$ The electronic wave functions were expanded in plane waves using an energy cutoff of $500 \mathrm{eV}$, and the reciprocal space was sampled using a $4 \times 4 \times 4$ Gamma-centered $k$-point mesh for DFT+U, a $2 \times 2 \times 2$ Gamma-centered $k$-point mesh for HSE06. The energy and force convergence criterion for the structural relaxation was set to $1 \times 10^{-4} \mathrm{eV}$ and $0.01 \mathrm{eV} / \AA$, respectively. To find the minimum energy path (MEP), the transition states for proton transfer between two oxygen sites were located using the climbing image nudged elastic band method (CI-NEB). ${ }^{9,10}$

To overcome the self-interaction error of the current exchange correlation functional for describing the $3 d$ orbitals of the transition metals, we employed the hybrid functional (HSE06) method. ${ }^{11,12}$ In this approach, the long-range exchange potential and the correlation potential are calculated using the PBE functional, whereas the short-range exchange potential is calculated by mixing a fraction of nonlocal Hartree-Fock exchange with that of PBE. To prove the accuracy of HSE06 for 
description of the electronic structures, we compared the band-gap calculated by HSE06 with the result obtained by DFT+U method (Table S2). We applied an on-site Hubbard term $\mathrm{U}_{\text {eff }}=(\mathrm{U}-\mathrm{J})$ acting to open-shell $3 d$ electrons of $\mathrm{Ni}, \mathrm{Co}$, and $\mathrm{Fe}$ atoms with $6.2,{ }^{13} 3.5,{ }^{14} 4.0 \mathrm{eV},{ }^{15}$ respectively, which are adopted from the literature. From the Table S2, when the HSE06 function is used for the $\mathrm{La}_{2} \mathrm{NiO}_{4}$ and $\mathrm{La}_{2} \mathrm{CoO}_{4}$, the calculated electronic properties are closer to the reference's values. However, for $\mathrm{La}_{2} \mathrm{NiO}_{4}$ and $\mathrm{La}_{2} \mathrm{CoO}_{4}$, the Hubbard $\mathrm{U}$ correction for the transition-metal $d$ orbitals artificially localizes the electrons on the $\mathrm{Ni}$ and $\mathrm{Co}$ atoms, did not correctly describe the self-interaction energy of La atoms, thus resulting in a small band-gap. The HSE06 methods that mix in a fraction of Hartree-Fock exact-exchange energy represent one possible improvement as the Hartree-Fock method explicitly cancels the self-interaction energy. The fact that these mixing parameters, optimized to reproduce electronic structure, also significantly improve the energetics (Table S3). Therefore, HSE06 yields more accurate formation energies and electronic structure s than DFT+U.

Table S1. The lattice parameters for the fully relaxed $\mathrm{La}_{2} \mathrm{NiO}_{4}, \mathrm{La}_{2} \mathrm{CoO}_{4}, \mathrm{Sr}_{2} \mathrm{CoO}_{4}$, and $\mathrm{Sr}_{2} \mathrm{FeO}_{4}$.

\begin{tabular}{|c|c|c|c|c|c|c|c|c|}
\hline lattice parameters $(\AA)$ & \multicolumn{2}{|c|}{$\mathrm{La}_{2} \mathrm{NiO}_{4}$} & \multicolumn{2}{|c|}{$\mathrm{La}_{2} \mathrm{CoO}_{4}$} & \multicolumn{2}{|c|}{$\mathrm{Sr}_{2} \mathrm{CoO}_{4}$} & \multicolumn{2}{|c|}{$\mathrm{Sr}_{2} \mathrm{FeO}_{4}$} \\
\hline \multirow{2}{*}{ This work } & $a=b$ & $\mathrm{c}$ & $a=b$ & $\mathrm{c}$ & $a=b$ & $\mathrm{c}$ & $a=b$ & $\mathrm{c}$ \\
\hline & 3.903 & 12.554 & 3.825 & 12.869 & 3.842 & 12.520 & 3.835 & 12.596 \\
\hline $\operatorname{Ref}^{5-8}$ & 3.865 & 12.670 & 3.904 & 12.901 & 3.796 & 12.487 & 3.864 & 12.397 \\
\hline Error & $0.98 \%$ & $0.91 \%$ & $1.77 \%$ & $0.25 \%$ & $1.21 \%$ & $0.26 \%$ & $0.75 \%$ & $1.61 \%$ \\
\hline
\end{tabular}

Table S2. The band-gap $\left(E_{g}\right)$ for pristine $\mathrm{La}_{2} \mathrm{NiO}_{4}, \mathrm{La}_{2} \mathrm{CoO}_{4}, \mathrm{Sr}_{2} \mathrm{CoO}_{4}$, and $\mathrm{Sr}_{2} \mathrm{FeO}_{4}$ calculated by DFT+U and HSE06. 


\begin{tabular}{c|c|c|c|c}
\hline \multirow{2}{*}{$E_{\mathrm{g}}$} & $\mathrm{La}_{2} \mathrm{NiO}_{4}$ & $\mathrm{La}_{2} \mathrm{CoO}_{4}$ & $\mathrm{Sr}_{2} \mathrm{CoO}_{4}$ & $\mathrm{Sr}_{2} \mathrm{FeO}_{4}$ \\
\hline DFT+U & $0.77 \mathrm{eV}$ & $0 \mathrm{eV}$ & $0 \mathrm{eV}$ & $0 \mathrm{eV}$ \\
\hline HSE06 & $1.99 \mathrm{eV}$ & $1.05 \mathrm{eV}$ & $0 \mathrm{eV}$ & $0 \mathrm{eV}$ \\
\hline Ref & $1.87-2.00 \mathrm{eV}^{16,17}$ & $1.20 \mathrm{eV}^{18}$ & $0 \mathrm{eV}^{19,20}$ & $0 \mathrm{eV}^{21,22}$ \\
\hline
\end{tabular}

Table S3. The formation energies $\left(E_{f}\right)$ for oxygen defects in $\mathrm{La}_{2} \mathrm{NiO}_{4}, \mathrm{La}_{2} \mathrm{CoO}_{4}, \mathrm{Sr}_{2} \mathrm{CoO}_{4}$, and $\mathrm{Sr}_{2} \mathrm{FeO}_{4}$ calculated by DFT+U and HSE06, and the error $(\Delta)$ between HSE06 and DFT+U.

\begin{tabular}{|c|c|c|c|c|c|c|c|c|c|c|c|c|}
\hline \multirow{2}{*}{$E_{f}(\mathrm{eV})$} & \multicolumn{3}{|c|}{$\mathrm{La}_{2} \mathrm{NiO}_{4}$} & \multicolumn{3}{|c|}{$\mathrm{La}_{2} \mathrm{CoO}_{4}$} & \multicolumn{3}{|c|}{$\mathrm{Sr}_{2} \mathrm{CoO}_{4}$} & \multicolumn{3}{|c|}{$\mathrm{Sr}_{2} \mathrm{FeO}_{4}$} \\
\hline & $\begin{array}{c}\text { DFT+ } \\
\mathrm{U}\end{array}$ & HSE06 & $\Delta$ & $\begin{array}{c}\text { DFT }+ \\
\mathrm{U}\end{array}$ & $\begin{array}{c}\text { HSE } \\
06\end{array}$ & $\Delta$ & $\begin{array}{c}\text { DFT }+ \\
\mathrm{U}\end{array}$ & $\begin{array}{c}\text { HSE0 } \\
6\end{array}$ & $\Delta$ & $\begin{array}{c}\text { DFT+ } \\
\mathrm{U}\end{array}$ & $\begin{array}{c}\text { HSE } \\
06\end{array}$ & $\Delta$ \\
\hline $\mathrm{V}_{\mathrm{O}}$ & 4.75 & 6.04 & 1.29 & 4.20 & 5.09 & 0.890 & -1.60 & -0.986 & 0.614 & -0.222 & 0.282 & 0.504 \\
\hline $\mathrm{O}_{\mathrm{i}}$ & -0.825 & -0.0302 & 0.795 & -2.87 & -2.08 & 0.790 & 0.209 & 0.931 & 0.722 & 2.43 & 3.05 & 0.620 \\
\hline $\mathrm{V}_{\mathrm{O}}+\mathrm{O}_{\mathrm{i}}$ & 1.24 & 2.04 & 0.800 & 0.636 & 1.37 & 0.734 & -0.740 & -0.182 & 0.558 & -0.133 & 0.318 & 0.548 \\
\hline
\end{tabular}

To evaluate the relative stability of different oxygen defects and the inherently nonstoichiometric oxygen, the formation energies $\left(E^{f}\right)$ of $\mathrm{V}_{\mathrm{O}}, \mathrm{O}_{\mathrm{i}}$, and $\mathrm{V}_{\mathrm{O}}+\mathrm{O}_{\mathrm{i}}$ defects were calculated as ${ }^{23,24}$

$$
E^{f}=E_{\mathrm{defect}}^{\mathrm{tot}}-E_{\mathrm{bulk}}^{\mathrm{tot}}+\sum_{i} \Delta n_{i} E_{i}
$$

where $E_{\mathrm{defect}}^{\text {tot }}$ and $E_{\mathrm{bulk}}^{\text {tot }}$ are the total energies of the nonstoichiometric systems containing defects and the bulk systems without any defects, $\mathrm{n}_{i}$ denotes the number of atoms of species $i$ that have been added or removed in the defective cell, and $E_{\mathrm{i}}$ are the corresponding energies from the respective molecules. A negative $E^{f}$ indicates that the stability of the defects. 
Hydration energies $\left(E_{\text {hydr }}\right)$ relative to the insertion of water on the defective sites were calculated as ${ }^{24,25}$

$$
E_{\text {hydr }}=E_{2 \mathrm{OH}}^{\mathrm{tot}}-E_{\text {defect }}^{\mathrm{tot}}-E_{\mathrm{H}_{2} \mathrm{O}}
$$

from the stoichiometric cell containing two proton defects $\left(E_{2 \mathrm{OH}}^{\text {tot }}\right)$, a cell containing a $\mathrm{V}_{\mathrm{O}}$ defect site or $\mathrm{V}_{\mathrm{O}}+\mathrm{O}_{\mathrm{i}}$ defects $\left(E_{\text {defect }}^{\text {tot }}\right)$, and an isolated water molecule $\left(E_{\mathrm{H}_{2} \mathrm{O}}\right)$. 
(a)

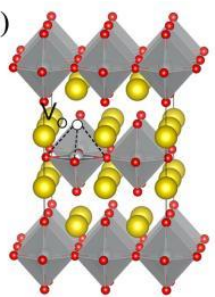

(b)

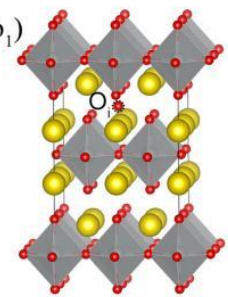

$\left(\mathrm{c}_{1}\right)$

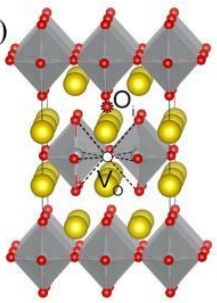

(a)

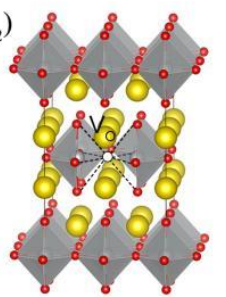

(b)

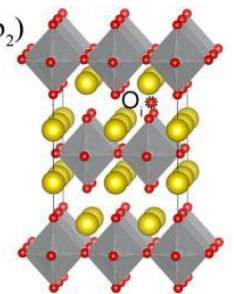

(c,

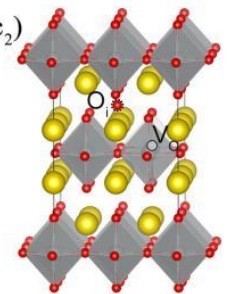

(a)

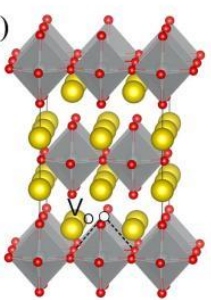

$\left(\mathrm{b}_{3}\right)$

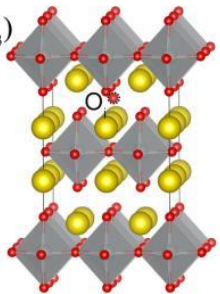

$\left(c_{3}\right)$

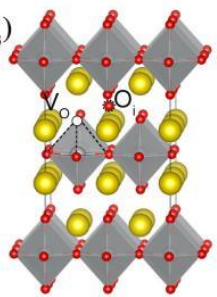

Figure S1. The oxygen defect configurations in $\mathrm{A}_{2} \mathrm{BO}_{4}\left(\mathrm{La}_{2} \mathrm{NiO}_{4}, \mathrm{La}_{2} \mathrm{CoO}_{4}, \mathrm{Sr}_{2} \mathrm{CoO}_{4}, \mathrm{Sr}_{2} \mathrm{FeO}_{4}\right)$ system. The configurations of ( $\left.a_{1}-a_{3}\right)$ oxygen vacancy $\mathrm{V}_{0}$ defect, $\left(\mathrm{b}_{1}-\mathrm{b}_{3}\right)$ interstitial oxygen $\mathrm{O}_{\mathrm{i}}$ defect, and $\left(\mathrm{c}_{1}-\mathrm{c}_{3}\right) \mathrm{V}_{\mathrm{O}}+\mathrm{O}_{\mathrm{i}}$ defect pair. The yellow and gray represents the atom at the $\mathrm{A}$ and $\mathrm{B}$ position, respectively.

Table S4. The formation energies $\left(E_{f}\right)$ for defects corresponding to the configuration in Figure S1 by HSE06.

\begin{tabular}{|c|c|c|c|c|c|c|c|c|c|}
\hline \multirow{2}{*}{$E_{f}(\mathrm{eV})$} & \multicolumn{3}{|c|}{$\mathrm{V}_{\mathrm{O}}$} & \multicolumn{3}{|c|}{$\mathrm{O}_{\mathrm{i}}$} & \multicolumn{3}{|c|}{$\mathrm{V}_{\mathrm{O}}+\mathrm{O}_{\mathrm{i}}$} \\
\hline & $a_{1}$ & $\mathrm{a}_{2}$ & a3 & $b_{1}$ & $\mathrm{~b}_{2}$ & $\mathrm{~b}_{3}$ & $\mathrm{c}_{1}$ & $\mathrm{c}_{2}$ & $\mathrm{c}_{3}$ \\
\hline $\mathrm{La}_{2} \mathrm{NiO}_{4}$ & 7.05 & 6.04 & 7.15 & $\begin{array}{c}-0.007 \\
75\end{array}$ & $\begin{array}{c}-0.030 \\
2\end{array}$ & $\begin{array}{c}-0.059 \\
3\end{array}$ & 2.69 & 2.71 & 2.04 \\
\hline $\mathrm{La}_{2} \mathrm{CoO}_{4}$ & 5.75 & 5.09 & 5.83 & -2.04 & -2.08 & -1.85 & 1.47 & 1.932 & 1.37 \\
\hline $\mathrm{Sr}_{2} \mathrm{CoO}_{4}$ & $\begin{array}{c}-0.30 \\
0\end{array}$ & -0.986 & $\begin{array}{c}-0.35 \\
4\end{array}$ & 1.35 & 0.931 & 0.994 & 1.10 & 0.669 & -0.182 \\
\hline $\mathrm{Sr}_{2} \mathrm{FeO}_{4}$ & 0.719 & 0.282 & $\begin{array}{c}0.67 \\
4\end{array}$ & 3.06 & 3.05 & 3.08 & 3.57 & 3.43 & 0.318 \\
\hline
\end{tabular}



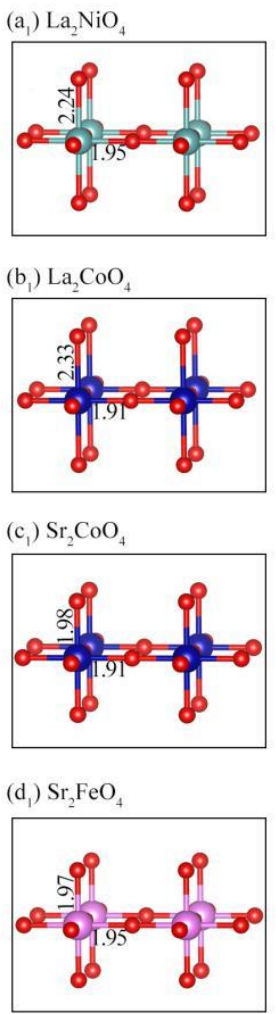
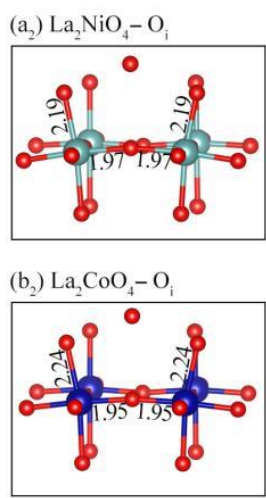

(c) $\mathrm{Sr}_{2} \mathrm{CoO}_{4}-\mathrm{O}$

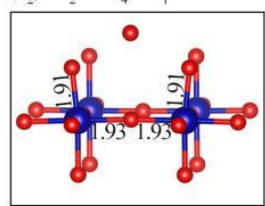

(d) $\mathrm{Sr}_{2} \mathrm{FeO}_{4}-\mathrm{O}$

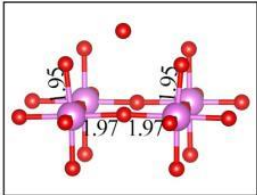

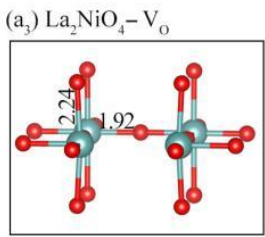

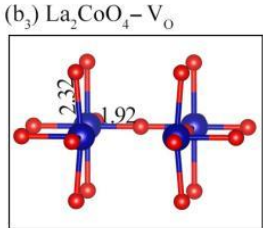

(c) $\mathrm{Sr}_{2} \mathrm{CoO}_{4}-\mathrm{V}_{\mathrm{o}}$

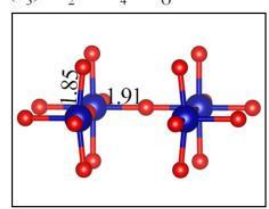

(d) $\mathrm{Sr}_{2} \mathrm{FeO}_{4}-\mathrm{V}_{\mathrm{o}}$

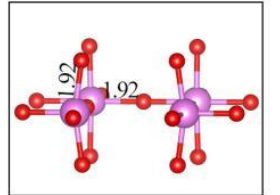

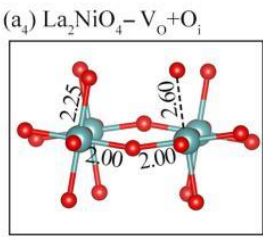

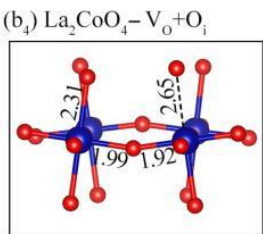

(c) $\mathrm{Sr}_{2} \mathrm{CoO}-\mathrm{V}_{0}+\mathrm{O}$

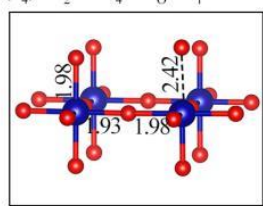

(d) $\mathrm{Sr}_{2} \mathrm{FeO}_{4}-\mathrm{V}_{\mathrm{o}}+\mathrm{O}$

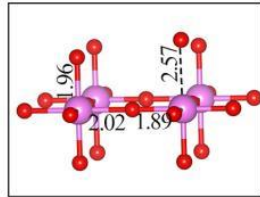

Figure S2. The local structures of different stable oxygen defect types in $\mathrm{La}_{2} \mathrm{NiO}_{4}, \mathrm{La}_{2} \mathrm{CoO}_{4}$, $\mathrm{Sr}_{2} \mathrm{CoO}_{4}$, and $\mathrm{Sr}_{2} \mathrm{FeO}_{4}$ systems. The green, blue, pink, and red balls indicate $\mathrm{Ni}, \mathrm{Co}, \mathrm{Fe}$, and $\mathrm{O}$ atoms. The distances between atoms at the $\mathrm{B}$ site $(\mathrm{Ni}, \mathrm{Co}$, and $\mathrm{Fe})$ and its neighboring $\mathrm{O}$ ions as well as those in the pristine material are presented in units of $\AA$.
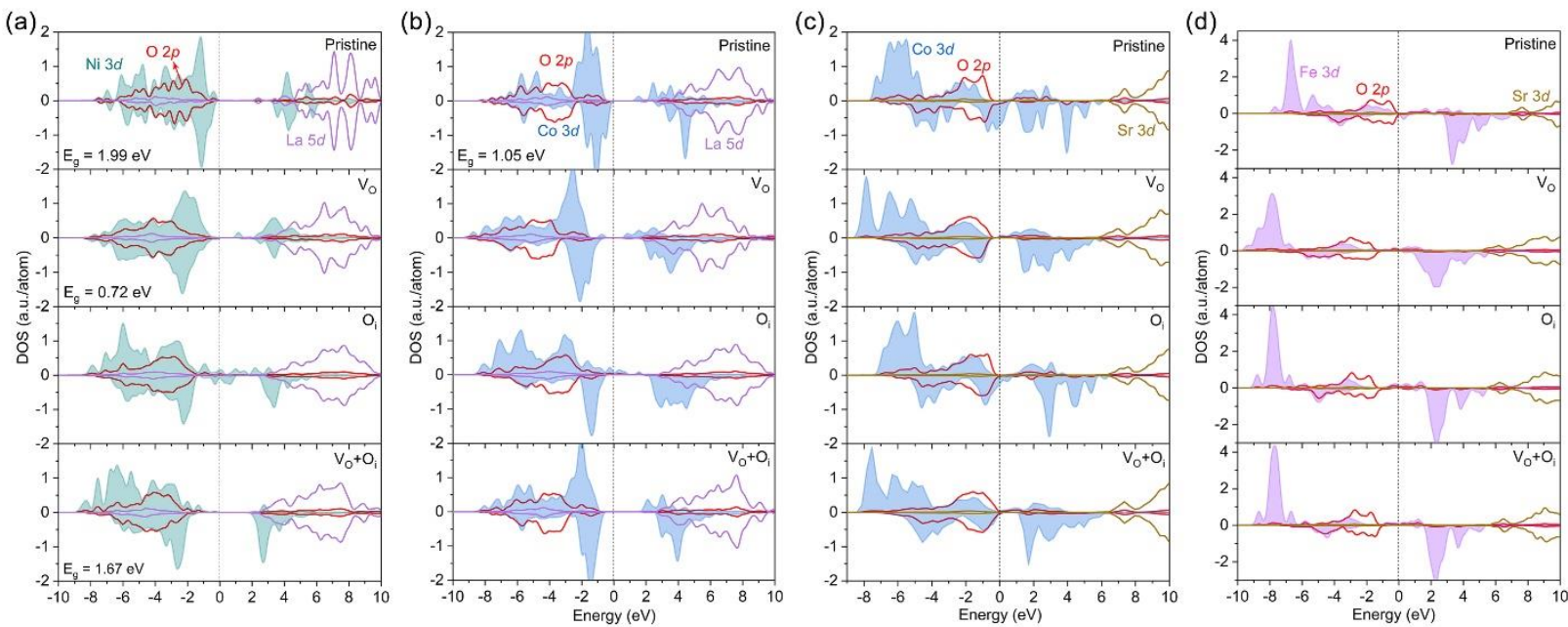

Figure S3. The partial density of states (PDOS) of pristine, $\mathrm{V}_{0}, \mathrm{O}_{i}$, and $\mathrm{V}_{\mathrm{O}}+\mathrm{O}_{i}$ defect in (a) $\mathrm{La}_{2} \mathrm{NiO}_{4}$, (b) $\mathrm{La}_{2} \mathrm{CoO}_{4}$, (c) $\mathrm{Sr}_{2} \mathrm{CoO}_{4}$, and (d) $\mathrm{Sr}_{2} \mathrm{FeO}_{4}$ systems. 


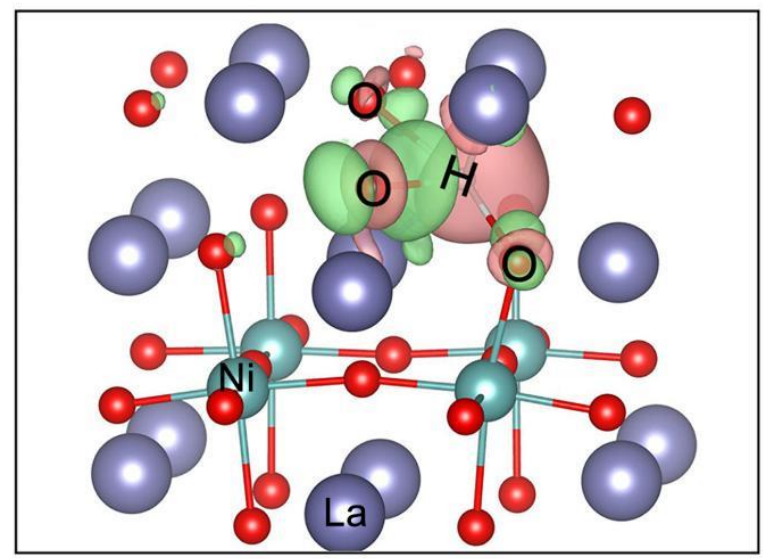

Figure S4. The charge density difference of the P4 transition state with highest migration barriers. The turquoise, and brownish-red regions represent electron depletion and accumulation, respectively.

(a)

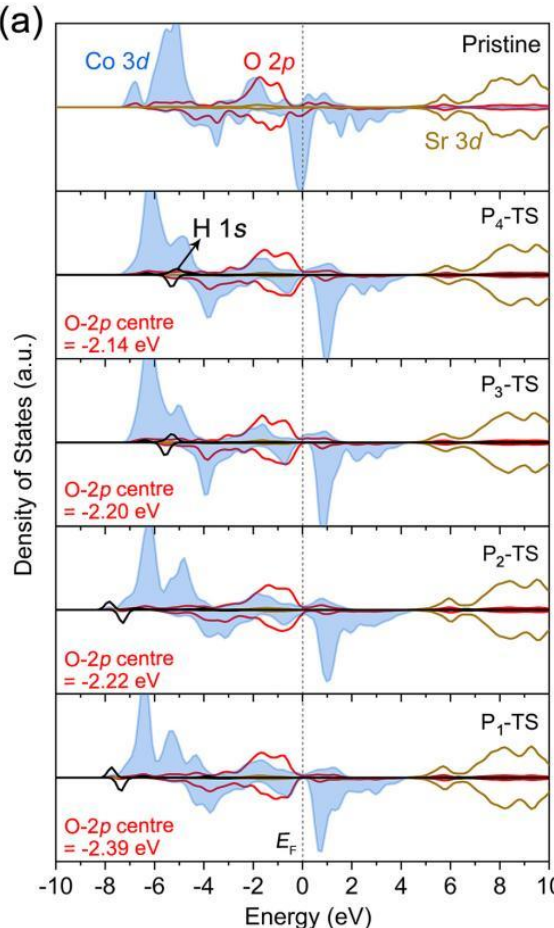

(b)

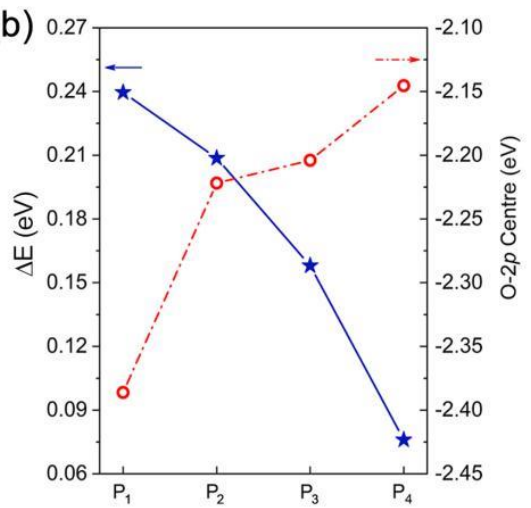

(c)

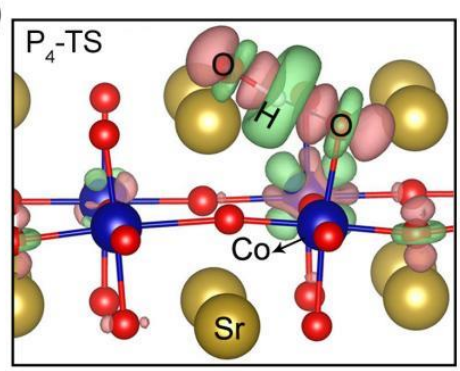

Figure S5. Electronic interpretation of the effect of proton defect on transportation and mobility in $\mathrm{Sr}_{2} \mathrm{CoO}_{4}$. (a) Computed the Co $3 d$, O $2 p$, and $\mathrm{Sr} 3 d$ PDOS of the transition state ( $\mathrm{P}_{1}-\mathrm{TS}, \mathrm{P}_{2}-\mathrm{TS}$, $\mathrm{P}_{3}$-TS, and $\mathrm{P}_{4}$-TS) by DFT $+\mathrm{U}$ method. (b) Migration energy barriers $(\Delta E)$ and the $\mathrm{O} 2 p$ band center relative to the $E_{\mathrm{F}}$ for $\mathrm{P}_{1}, \mathrm{P}_{2}, \mathrm{P}_{3}$, and $\mathrm{P}_{4}$ transition states. (c) The charge density difference of the $\mathrm{P}_{4}$ transition state with the lowest migration energy barriers by DFT $+\mathrm{U}$ method, the turquoise and brownish-red regions represent electron depletion and accumulation, respectively. 
(a)

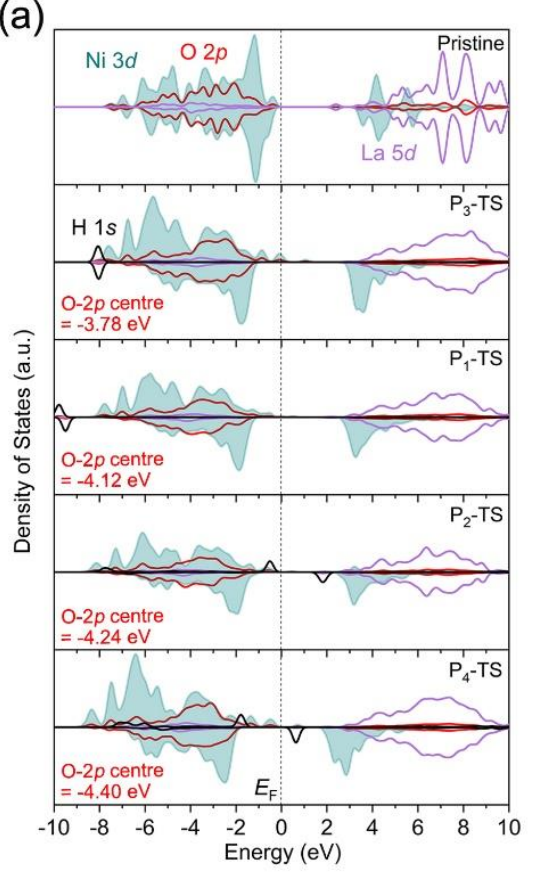

(b)

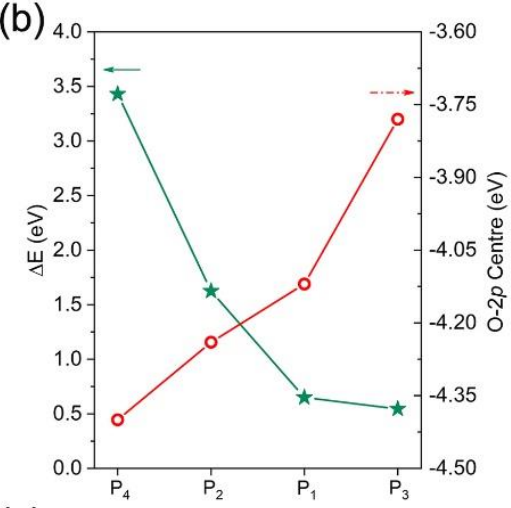

(c)

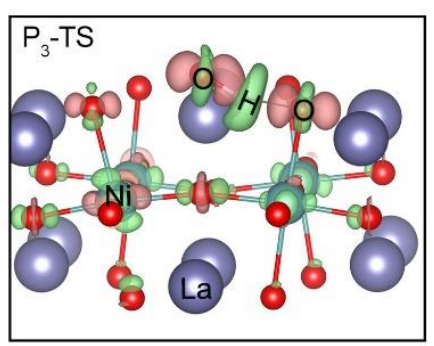

Figure S6. Electronic interpretation of the effect of proton defect on transportation and mobility in $\mathrm{La}_{2} \mathrm{NiO}_{4}$. (a) Computed the $\mathrm{Ni} 3 d$, O $2 p$, and La $5 d$ PDOS of the transition state ( $\mathrm{P}_{1}-\mathrm{TS}, \mathrm{P}_{2}-\mathrm{TS}$, $\mathrm{P}_{3}$-TS, and $\mathrm{P}_{4}$-TS) by HSE06 method. (b) Migration energy barriers $(\Delta E)$ and the $\mathrm{O} 2 p$ band center relative to the Fermi level for $\mathrm{P}_{1}, \mathrm{P}_{2}, \mathrm{P}_{3}$, and $\mathrm{P}_{4}$ transition state. (c) The charge density difference of the $\mathrm{P}_{3}$ transition state with the lowest migration barriers by HSE06 method, the turquoise, and brownish-red regions represent electron depletion and accumulation, respectively.

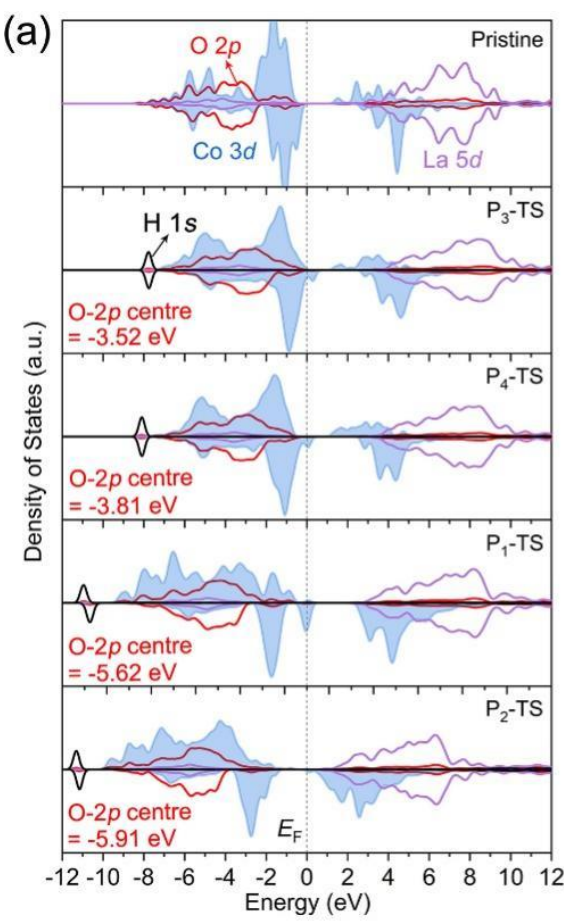

(b)

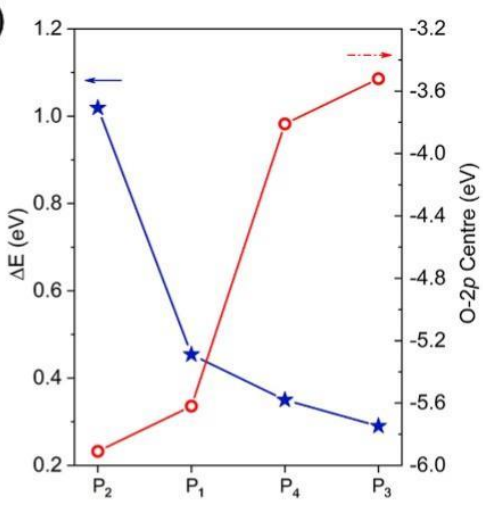

(c)

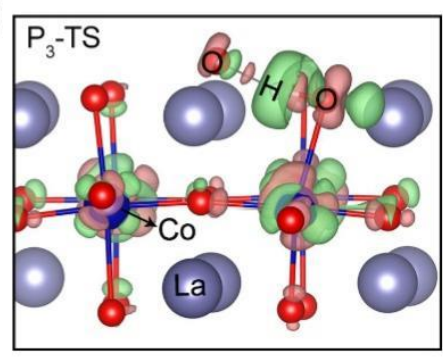


Figure S7. Electronic interpretation of the effect of proton defect on transportation and mobility in $\mathrm{La}_{2} \mathrm{CoO}_{4}$. (a) Computed the Co $3 d$, O $2 p$, and La $5 d$ PDOS of the transition state ( $\mathrm{P}_{1}-\mathrm{TS}, \mathrm{P}_{2}-\mathrm{TS}$, $\mathrm{P}_{3}$-TS, and $\mathrm{P}_{4}$-TS) by HSE06 method. (b) Migration energy barriers $(\Delta E)$ and the $\mathrm{O} 2 p$ band centre relative to the Fermi level for $\mathrm{P}_{1}, \mathrm{P}_{2}, \mathrm{P}_{3}$, and $\mathrm{P}_{4}$ transition state. (c) The charge density difference of the $\mathrm{P}_{3}$ transition state with the lowest migration barriers by HSE06 method, the turquoise, and brownish-red regions represent electron depletion and accumulation, respectively.

(a)

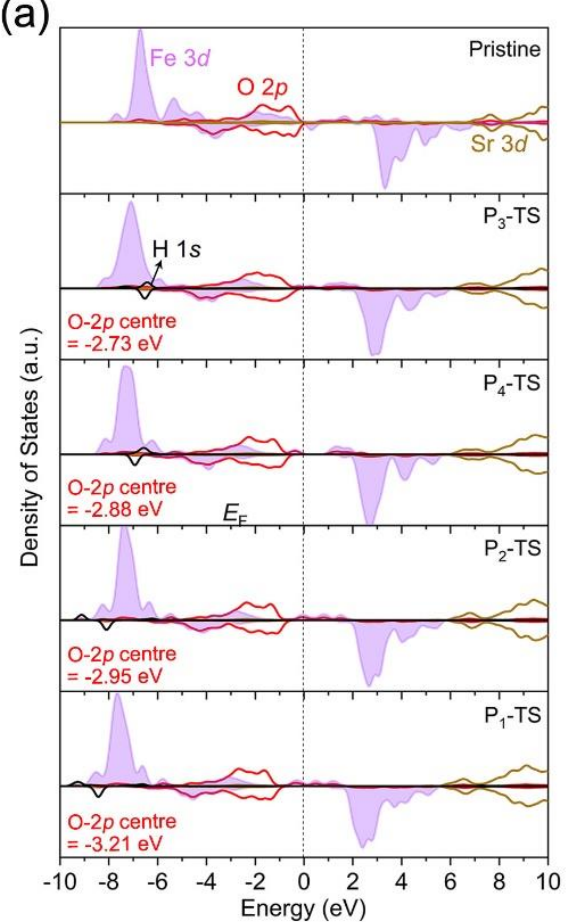

(b)

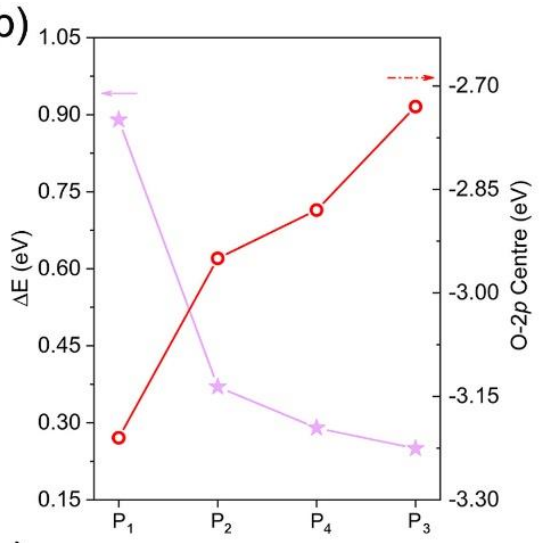

(c)

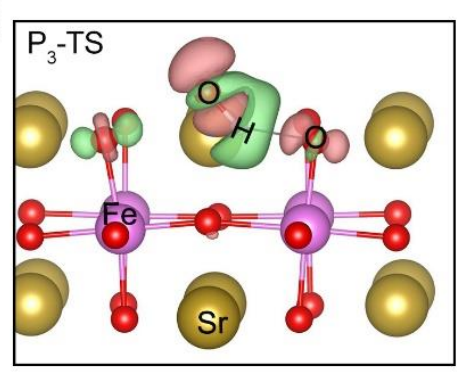

Figure S8. Electronic interpretation of the effect of proton defect on transportation and mobility in $\mathrm{Sr}_{2} \mathrm{FeO}_{4}$. (a) Computed the $\mathrm{Fe} 3 d, \mathrm{O} 2 p$, and $\mathrm{Sr} 3 d$ PDOS of the transition state ( $\mathrm{P}_{1}-\mathrm{TS}, \mathrm{P}_{2}-\mathrm{TS}, \mathrm{P}_{3}-\mathrm{TS}$, and $\mathrm{P}_{4}$-TS) by HSE06 method. (b) Migration energy barriers $(\Delta E)$ and the $\mathrm{O} 2 p$ band center relative to the Fermi level for $\mathrm{P}_{1}, \mathrm{P}_{2}, \mathrm{P}_{3}$, and $\mathrm{P}_{4}$ transition state. (c) The charge density difference of the $\mathrm{P}_{3}$ transition state with the lowest migration barriers by HSE06 method, the turquoise, and brownish-red regions represent electron depletion and accumulation, respectively. 


\section{REFERENCES}

(1) Kresse, G.; Furthmüller, J. Efficient iterative schemes for ab-initio total-energy calculations using a plane-wave basis set. Phys Rev B 1996, 54, 11169.

(2) Kresse, G.; Furthmüller, J. Efficiency of ab-initio total energy calculations for metals and semiconductors using a plane-wave basis set. Comput Mater Sci 1996, $6,15-50$

(3) Kresse, G.; Joubert D. From ultrasoft pseudopotentials to the projector augmented-wave method. Phys Rev B 1999, 59, 1758-1775.

(4) Perdew, J. P.; Burke, K.; Ernzerhof, M. Generalized gradient approximation made simple. Phys Rev Lett 1996, 77, 3865-3868.

(5) Tropin, E. S.; Ananyev, M. V.; Farlenkov, A. S.; Khodimchuk, A. V.; Berenov, A. V.; Fetisov, A. V.; Eremin, V. A.; Kolchugin, A. A. Surface defect chemistry and oxygen exchange kinetics in $\mathrm{La}_{2-\mathrm{x}} \mathrm{Ca}_{\mathrm{x}} \mathrm{NiO}_{4+\delta}$. J. Solid State Chem. 2018, 262, 199-213.

(6) Skinner, S. J.; Amow, G. Structural observations on $\mathrm{La}_{2}(\mathrm{Ni}, \mathrm{Co}) \mathrm{O}_{4 \pm \delta}$ phases determined from in situ neutron powder diffraction. J. Solid State Chem. 2007, $180,1977-1983$.

(7) Wang, X. L.; Takayama-Muromachi, E. Magnetic and transport properties of the layered perovskite system $\mathrm{Sr}_{2-\mathrm{y}} \mathrm{Y}_{\mathrm{y}} \mathrm{CoO}_{4}(0 \leqslant \mathrm{y} \leqslant 1)$. Phys. Rev. B 2005, 72, 064401.

(8) Dann, S. E.; Weller, M. T.; Currie, D. B.; Thomas, M. F.; Al-Rawwas, A. D. Structure and magnetic properties of $\mathrm{Sr}_{2} \mathrm{FeO}_{4}$ and $\mathrm{Sr}_{3} \mathrm{Fe}_{2} \mathrm{O}_{7}$ studied by powder neutron diffraction and Mössbauer spectroscopy. J. Mater. Chem. 1993, 3, 1231-1237.

(9) Henkelman, G.; Uberuaga, B. P.; Jonsson, H. A climbing image nudged elastic band method for finding saddle points and minimum energy paths. J. Chem. Phys. 2000, 113, 9901-9904.

(10) Sheppard, D.; Xiao, P.; Chemelewski, W.; Johnson, D. D.; Henkelman, G. A generalized solid-state nudged elastic band method. J. Chem. Phys. 2012, 136, 074103 . 
(11) Heyd, J.; Scuseria, G. E.; Ernzerhof, M. Hybrid Functionals Based on a Screened Coulomb Potential. J. Chem. Phys. 2003, 118, 8207-8215.

(12) Krukau, A. V.; Vydrov, O. A.; Izmaylov, A. F.; Scuseria, G. E. Influence of the exchange screening parameter on the performance of screened hybrid functionals. J. Chem. Phys. 2006, 125, 224106.

(13) Jain, A.; Hautier, G.; Ong, S. P.; Moore, C. J.; Fischer, C. C.; Persson, K. A.; Ceder, G. Formation enthalpies by mixing GGA and GGA+U calculations. Phys Rev B 2011, 84, 045115.

(14) Pandey, S. K.; Kumar, A.; Patil, S.; Medicherla, V. R. R.; Singh, R. S.; Maiti, K.; Prabhakaran, D.; Boothroyd, A. T.; Pimpale, A. V. Investigation of the spin state of $\mathrm{Co}$ in $\mathrm{LaCoO}_{3}$ at room temperature: $\mathrm{Ab}$ initio calculations and high-resolution photoemission spectroscopy of single crystals. Phys Rev B 2008, 77, 045123.

(15) Gu, X. K.; Nikolla, E. Design of Ruddlesden-Popper oxides with optimal surface oxygen exchange properties for oxygen reduction and evolution. ACS Catal. 2017, 7, 5912-5920.

(16) Liu, C. J.; Mays; M. D.; Cowan, D. O.; Sánchez, M. G. Composition-controlled metal-nonmetal transition in lanthanum strontium nickel oxide $\left(\mathrm{La}_{2-\mathrm{x}} \mathrm{Sr}_{\mathrm{x}} \mathrm{NiO}_{4-\delta}\right)$. Chem. Mater. 1991, 3, 495-500.

(17) Lahmar, H.; Benamira, M.; Douafer, S.; Messaadia, L.; Boudjerda, A.; Trari, M. Photocatalytic degradation of methyl orange on the novel hetero-system $\mathrm{La}_{2} \mathrm{NiO}_{4} / \mathrm{ZnO}$ under solar light. Chem. Phys. Lett. 2020, 742, 137132

(18) Wu, H.; Burnus, T. Spin and orbital states in $\mathrm{La}_{1.5} \mathrm{Sr}_{0.5} \mathrm{CoO}_{4}$ studied by electronic structure calculations. Phys. Rev. B 2009, 80, 081105.

(19) Pandey, S. K. Correlation induced half-metallicity in a ferromagnetic single-layered compound: $\mathrm{Sr}_{2} \mathrm{CoO}_{4}$. Phys. Rev. B 2010, 81, 035114

(20) Lee, K. W.; Pickett, W. E. Correlation effects in the high formal oxidation-state compound $\mathrm{Sr}_{2} \mathrm{CoO}_{4}$. Phys. Rev. B 2006, 73, 174428

(21) Rodrigues, J. N. B.; Wagner, L. K. Identifying materials with charge-spin physics using charge-spin susceptibility computed from first principles. J. Chem. Phys. 2020, 153, 074105 
(22) Rozenberg, G. K.; Milner, A. P.; Pasternak, M. P.; Hearne, G. R.; Taylor, R. D. Experimental confirmation of a p-p intraband gap in $\mathrm{Sr}_{2} \mathrm{FeO}_{4}$. Phys. Rev. B 1998, $58,10283$.

(23) Hoedl, M. F.; Gryaznov, D.; Merkle, R.; Kotomin, E. A.; Maier, J. Interdependence of oxygenation and hydration in mixed conducting $(\mathrm{Ba}, \mathrm{Sr}) \mathrm{FeO}_{3-\delta}$ perovskites studied by density functional theory. J. Phys. Chem. C 2020, 124, 11780-11789.

(24) Muñoz-García, A. B.; Tuccillo, M.; Pavone, M. Computational design of cobalt-free mixed proton-electron conductors for solid oxide electrochemical cells. J. Mater. Chem. A 2017, 5, 11825.

(25) Munoz-Garcia, A. B.; Pavone, M. First-principles design of new electrodes for proton-conducting solid-oxide electrochemical cells: A-site doped $\mathrm{Sr}_{2} \mathrm{Fe}_{1.5} \mathrm{Mo}_{0.5} \mathrm{O}_{6-\delta}$ perovskite. Chem. Mater. 2016, 28, 490-500. 